Article

\title{
Sulfated Glycoaminoglycans and Proteoglycan Syndecan-4 Are Involved in Membrane Fixation of LL-37 and Its Pro-Migratory Effect in Breast Cancer Cells
}

\author{
Chahrazed Habes ${ }^{1}$, Günther Weber ${ }^{1, *(1)}$ and Caroline Goupille ${ }^{1,2}$ \\ 1 INSERM, Université de Tours, UMR 1069 Nutrition, Growth and Cancer, 37032 Tours, France; \\ chahrazed.habes@etu.univ-tours.fr (C.H.); caroline.goupille@univ-tours.fr (C.G.) \\ 2 CHRU de Tours, Hôpital Bretonneau, 37032 Tours, France \\ * Correspondence: gunther.weber@univ-tours.fr; Tel.: +33-247-366-294
}

Received: 27 July 2019; Accepted: 10 September 2019; Published: 12 September 2019 updates

\begin{abstract}
Initially characterized by its antimicrobial activities, LL-37 has also been shown to significantly contribute to tumor development. On breast cancer cell lines, LL-37 increases intracellular calcium via the TRPV2 channel and their migration via the activation of PI3K/AKT signaling. Its all-D enantiomer D-LL-37 induces similar effects, which excludes a protein-protein interaction of LL-37 in a classic ligand-receptor manner. Its net charge of +6 gave rise to the hypothesis that the peptide uses the negative charges of sulfoglycans or sialic acids to facilitate its attachment to the cell membrane and to induce its activities. Whereas several vegetal lectins, specifically attaching to sialylated or sulfated structures, blocked the activities of LL-37 on both calcium increase and cell migration, several sialidases had no effect. However, the competitive use of free sulfated glycoaminoglycans (GAGs) as chrondroitin and heparin, or treatment of the cell surface with chondroitinase and heparinase resulted in an activity loss of $50-100 \%$ for LL-37. Concordant results were obtained by blocking the synthesis of GAGs with 4-Methylumbelliferyl- $\beta$-D-xyloside, and by suppression of glycan sulfatation by sodium chlorate. Using a candidate approach by suppressing proteoglycan synthesis using RNA interference, syndecan-4 was shown to be required for the activities of LL-37 and its binding to the cell surface. This leads to the conclusion that syndecan-4, by means of sulfated GAGs, could act as a receptor for LL-37.
\end{abstract}

Keywords: LL-37; breast cancer; glycosaminoglycans; syndecan; cell migration

\section{Introduction}

The LL-37 peptide is released from the C-terminus of the Human Cathelicidin Antimicrobial Protein hCAP18. Initially characterized by its antimicrobial activities, LL-37 is now considered as multifunctional, inducing chemotaxis, stimulating angiogenesis and promoting tissue repair [1,2]. Increasing evidence has demonstrated a significant role in a variety of cancer where, depending on the cancer origin, both pro- and antitumorigenic effects have been reported [3,4].

Mechanistically, these activities have been linked to the activation of multiple membrane-associated proteins, transmembrane receptors of different classes as well as ion channels [4,5]. Some of them have been suggested as being direct receptors for LL-37, although their physical interaction remains to be characterized. However, their variety and structural diversity did not suggest a conventional receptor-ligand binding of LL-37 to these proteins as a common denominator for their activation. In cell proliferation studies on lung cancer cell lines [6] and NIH3T3 fibroblasts [7], the all- D- enantiomer of LL-37 showed activities identical to those of the wildtype L- enantiomer. Likewise, the promigratory 
activities of LL-37, depending on AKT signaling and the activation of the TRPV2 $\mathrm{Ca}^{2+}$-channel, were induced by both L- and D-enantiomer [8]. Binding of LL-37 to the cell membrane has been shown to reduce the mobility of membrane receptors of dendritic cells and keratinocytes [9], and to decrease cell membrane fluidity of breast cancer cells [8]. This suggested that LL-37 may influence transmembrane receptors through indirect mechanisms of action, by binding to the membrane interface.

Binding studies of LL-37 on bacterial membranes [10] and model micelles [11-14] have demonstrated that it adopts the conformation of an amphipathic helix, inserting its hydrophobic site within the hydrophobic/hydrophilic interface. Phospholipids increased binding of LL-37 [13], whereas cholesterol was shown to attenuate its attachment [14].

On the MDA-MB-435s cancer cell line, however, LL-37 was localized at the surface of pseudopodia and caveolae [8]. These structures are known to harbor receptors activated by LL-37 [15-17] but are rich in cholesterol, which should have prevented LL-37 from binding to the membrane. To explain this contradiction, we hypothesized that LL-37 needed to associate with nonlipid structures in addition to the lipid bilayer.

Some scattered data have previously demonstrated that glycans may play a role in regulating the activities of LL-37. Its antimicrobial activities in the airway can be suppressed by binding to mucins, probably due to unspecific interactions between the positively charged peptide and the negatively charged glycans [18]. Similarly, its proinflammatory activities on epithelial cells and macrophages can be neutralized by a synthetic glycan [19]. An active role of proteoglycans in lipid rafts was demonstrated for the endocytosis of a LL-37-DNA complex [20] and the uptake of lipopolysaccharides mediated by LL-37 [21]. It thus appeared conceivable to investigate the impact of proteoglycans to the activities of LL-37 in cancer cells.

We hypothesized that LL-37, due to its six positive charges, might interact with negatively charged glycans (sialic acid or sulfated glycans). We thus tried to identify glycans and glycoproteins able to transduce the LL-37 activities we have characterized previously, i.e., stimulation of constitutive calcium entry and cell migration on our mammary tumor cell lines.

\section{Materials and Methods}

\subsection{Cell Lines}

MCF7, MDA-MB-435s and MDA-MB-231 cell lines were obtained from ATCC (via LGC Standards, Molsheim, France) and grown in Dulbecco's modified Eagle's medium (DMEM) containing $4.5 \mathrm{~g} / \mathrm{L}$ glucose, supplemented with $10 \%$ fetal calf serum (FCS) (Eurobio, Courtaboeuf, France). Cells were grown at $37^{\circ} \mathrm{C}$ in a humidity saturated atmosphere containing $5 \% \mathrm{CO}_{2}$. The cells were reseeded $48 \mathrm{~h}$ prior to the experiments described below.

\subsection{Peptides, Inhibitors and Antibodies Used in this Study}

The LL-37 peptide (Sequence: LLGDFFRKSK EKIGKEFKRI VQRIKDFLRN LVPRTES) and its enantiomer D-LL-37 were synthesized and HPLC-purified to $>95 \%$ (GeneCust, Dudelange, Luxembourg, and GL Biochemicals, Shanghai, China). All experiments were performed at $10 \mu \mathrm{g} / \mathrm{mL}(2.2 \mu \mathrm{M})$ of peptide if not mentioned otherwise. Enzymes, inhibitors and antibodies and the concentration used in this study are listed in Supplementary Tables S1 and S2.

\subsection{Cell Migration Assay}

Twenty four hours before cell migration experiments cells were adapted to the migration medium, DMEM containing $0.1 \%$ FCS and $0.1 \%$ Bovine Serum Albumin (BSA). Cells (30,000 for MDA-MB-453s and MDA-MB-231, 60,000 for MCF7) suspended in $300 \mu \mathrm{L}$ of migration medium at the upper side of a migration chamber (Insert with Polyethylene filter with $8 \mu \mathrm{M}$ pores, Falcon BD Biosciences, Le Pont de Claix, France), together with the enzymes or inhibitors at the concentrations listed in Supplementary Table S1. Inhibition with 4-Methylumbelliferyl- $\beta$-D-xyloside and sodium chlorate 
required a pretreatment for $48 \mathrm{~h}$ at $1 \mathrm{mM}$ and $30 \mathrm{mM}$, respectively, before the migration experiment. The lower chamber was filled with $800 \mu \mathrm{L}$ of migration medium containing or not LL-37. After $5 \mathrm{~h}$ for MDA-MB-453s and MDA-MB-231 and $24 \mathrm{~h}$ for MCF7, cells were fixed with methanol and stained with DAPI at $1 \mu \mathrm{g} / \mathrm{mL}$, and counted in a fluorescent microscope using Image J (https://imagej.net). To highlight the potential inhibitory effects of reagents, results are normalized to migration of cells with LL-37. In all migration experiments, controls are performed using 5\% FCS as attractant, to monitor unspecific effects of the reagents used in the study.

\subsection{Measurements of Intracellular $\mathrm{C} \alpha^{2+}$ Variation}

Intracellular $\mathrm{Ca}^{2+}$ concentration variations were detected using the fluorimetric assay with Fura2-AM (a ratiometric probe for intracellular $\mathrm{Ca}^{2+}$ ) as essentially described [8]. Intracellular $\mathrm{Ca}^{2+}$ variations were evaluated using the fluorescence $(510 \mathrm{~nm})$ emission ratio at excitations at 340 and $380 \mathrm{~nm}$. This ratio is directly related to the amount of intracellular calcium. Briefly, measurement started when cells were suspended in buffer without $\mathrm{Ca}^{2+}$, for recording the basal fluorescence level. After $20 \mathrm{~s}, \mathrm{Ca}^{2+}$ was applied at $2 \mathrm{mM}$ leading to calcium influx through opened membrane calcium channels (Control calcium level). To evaluate LL-37 and the effects of inhibitors, they were added to the resuspended cells just before the beginning of the measurement. The fluorescence level obtained for cells in presence of $2 \mathrm{mM}$ calcium and LL-37 was used as reference to normalize subsequent measurements. To calculate the effect of inhibitors to LL-37, the normalized Ca influx in presence of LL37 (100\%) and the channel activity at $2 \mathrm{mM} \mathrm{Ca}$ and in absence of LL-37 (0\%-indicated as a horizontal line in the graphs) are used as reference points.

\subsection{Immunofluorescence Labeling}

Forty eight hours before experiment, 20,000 cells were seeded in black plate with transparent flat well (96 wells, 10082471, Corning, Wiesbaden, Germany). The medium was replaced for $24 \mathrm{~h}$ with OPTI-MEM (Life Technologies, Saint Aubin, France) with 0.2\% Bovine Serum Albumin (BSA, Sigma-Aldrich, St. Quentin Fallavier, France). Enzymes or inhibitors (for concentration see Supplementary Table S1) were applied in D-PBS with 1\% BSA for $1 \mathrm{~h}$. After two washes in D-PBS, LL-37 was incubated at $10 \mu \mathrm{g} / \mathrm{mL}$ for $10-15 \mathrm{~min}$ at $4{ }^{\circ} \mathrm{C}$; then, cells were fixed with Paraformaldehyde $4 \%$ as described in [8]. For the detection of LL-37, a mouse monoclonal antibody [22] was used at $2 \mu \mathrm{g} / \mathrm{mL}$.

\subsection{RNA Interference and Expression Analysis by Quantitative Real-Time Polymerase Chain Reaction ( $q R T-P C R)$}

The siRNAs used in this study are listed in Supplementary Table S2. Cells were transfected in suspension using Lipofectamine RNAiMax (Fisher Scientific, Illkirch, France) according to the manufacturer's protocol, at a final siRNA concentration of $25 \mathrm{nM}$. Cells were seeded in six-well plates at 250,000 per well. Experiments were then performed $72 \mathrm{~h}$ after transfection. While for all experiments on syndecan-1 and syndecan-4 published siRNA were used [23,24], an additional siRNA was designed for migration experiments on MDA-MB-435s to ascertain the specificity of the observations on syndecan-4 suppression.

Transcript suppression was determined by qRT-PCR $72 \mathrm{~h}$ post transfection. For expression analysis, total RNA was extracted using the NucleoSpin ${ }^{\circledR}$ RNA II kit (Macherey-Nagel, Hoerdt, France), and reverse transcribed using the PrimeScript ${ }^{\mathrm{TM}}$ RT Reagent Kit (Perfect Real Time, TAKARA, Nice, France). Gene quantification was performed in the LightCycle ${ }^{\circledR} 480$ II (ROCHE) thermocycler, with $20 \mathrm{ng}$ of $\mathrm{cDNA}$ using the SYBR ${ }^{\circledR}$ Premix Ex Taq ${ }^{\mathrm{TM}}$ (Tli RNaseH Plus, TAKARA) kit at a final volume of $10 \mu \mathrm{L}$. Primers were used at a final concentration of $500 \mathrm{nM}$ and are listed in Supplementary Table S2. After preincubation at $50{ }^{\circ} \mathrm{C}$ for $5 \mathrm{~min}$ and $95^{\circ} \mathrm{C}$ for $10 \mathrm{~min}, 45$ amplification cycles $\left(95^{\circ} \mathrm{C}\right.$ $10 \mathrm{~s}, 60{ }^{\circ} \mathrm{C} 30 \mathrm{~s}, 72{ }^{\circ} \mathrm{C} 20 \mathrm{~s}$ ) were performed. The expression was determined relative to HPRT1 as reference, and expressed using the $\Delta \Delta \mathrm{Ct}$ method [25]. 


\subsection{Statistic Analysis}

The significance of the results was determined by Mann-Whitney non-parametric statistics. The results are expressed as means \pm SEM. The significance was indicated by stars $\left(^{*} p<0.05,{ }^{* *} p<0.01\right.$, $\left.{ }_{* * *} p<0.001\right)$. The number $\mathrm{N}$ of independent measurements is indicated in the figure legends.

\section{Results}

\subsection{The Activities of LL-37 Are Blocked by Lectins but Do Not Require $\alpha 2-3-$ or $\alpha 2-6$-Linked Sialic Acids}

Since we assumed that the activities of LL-37 on the cancer cell might be reduced by blocking glycans on the cell surface, our first strategy was to mask negatively charge glycans such as sialic acid using lectins.

Four lectins, Maackia amurensis Agglutinin I and II (MAA I, MAA II, $\alpha 2-3$ sialic acid specificity), lectin Sambucus nigra Agglutinin (SNA, $\alpha 2-6$ sialic acid specificity) and an irrelevant lectin Peanut Agglutinin (PNA, galactose specificity) were assayed during cell migration, which we initially used as a reporter experiment for the activities of LL-37. The $\alpha 2-3$ or $\alpha 2-6$-linked sialic acids were markedly present on MDA-MB-231 and MDA-MB-435s as shown in Supplementary Figure S1. However, since glycosylation patterns vary in cancer tissues and cell lines and depend on their origin and malignancy [26-28], three cell lines, MDA-MB-435s, MDA-MB-231 and MCF7, were compared in the experiments. In all cell lines, only lectins MAA I and MAA II, which bind terminal $\alpha 2-3$-linked sialic acid [29] significantly reduced cell migration (Figure 1a), whereas SNA and PNA showed no suppressive effect. The level of suppression varied among the lines: in presence of MAA I and II, migration of MDA-MB-231was suppressed by $50 \%$ and 30\%, respectively, by $50 \%$ for both lectins for MDA-MB-435s, and 100\% and 40\%, respectively, for MCF7. With the exception of MAA I on MDA-MB-435s, lectins did not suppress cell migration in control experiments, in which 5\% FCS was used as chemoattractant (not shown).

We have previously shown that the promigratory activity of LL-37 in breast cancer cell lines is linked to the activation of the TRPV2 Ca-channel [8] and influx of extracellular calcium. As demonstrated in Figure $1 b$, this activity was almost totally abrogated in presence of lectins MAA I, MAA II and SNA for MDA-MB-231 and significantly reduced by $45 \%$ in MDA-MB- 435 s with both lectins MAA I and MAA II. The basic influx of extracellular calcium remained unaltered in the presence of lectins alone (Figure 1b). An apparent difference was observed on the treatment with the SNA lectin, which induced increased migration despite decrease of calcium. However, control experiments with 5\% FCS as chemoattractant revealed that this was due to an unspecific promigratory effect of SNA (Supplementary Figure S1a).

Throughout this article calcium measurements in MCF7 were not presented since calcium influx were too small to report reliable inhibitions. However, TRPV2 calcium influx implication in LL-37 activities in MCF7 has been previously demonstrated [8].

To gauge whether $\alpha 2-3$ - or $\alpha 2-6$-linked sialic acids were implicated in the activities of LL-37, two sialidases from Arthrobacter ureafaciens and Vibrio cholerae [30] were used to remove sialic acids from plasma membranes. Enzyme efficacies were performed in a control experiment performed in parallel, verifying a decrease of binding MAA lectins (Supplementary Figure S2b,c) and LL-37 peptide (Supplementary Figure S2d) on the cell plasma membrane. Removing sialic acids from membranes of MDA-MB-231 and MDA-MB-435s did not alter the promigratory effect of LL-37 (Figure 1c). Taken together, these results suggested that sialic acids contributed to LL-37 fixation on the plasma membrane but were not involved in the promigratory activities LL-37. 
a

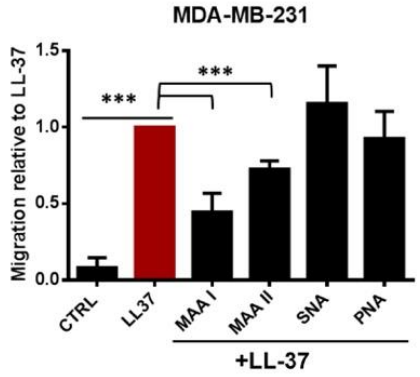

b

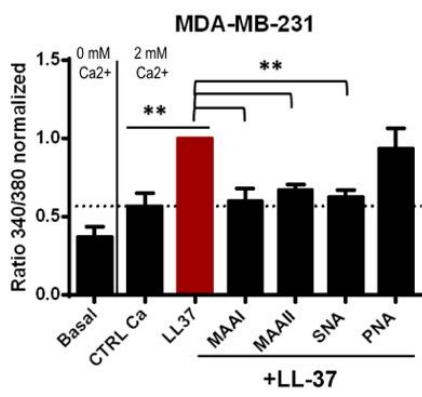

C

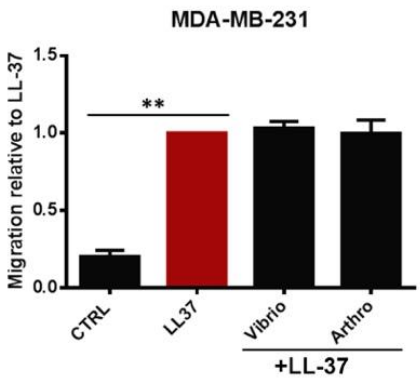

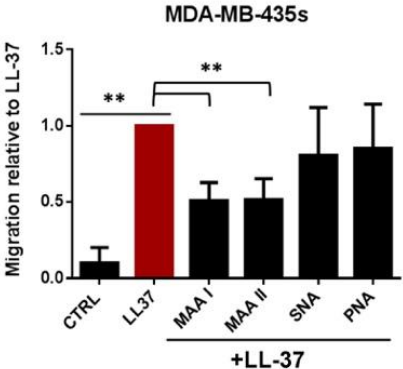
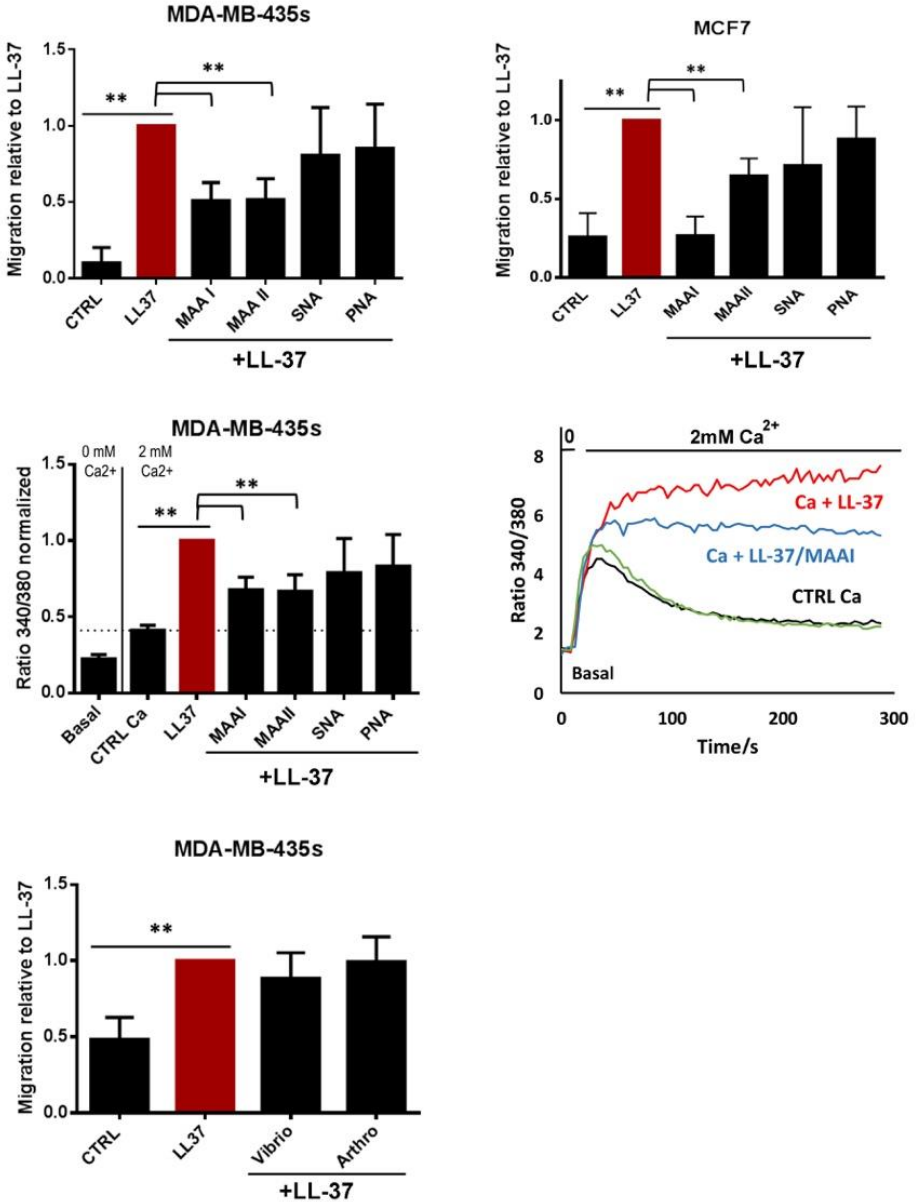

Figure 1. LL-37-induced migration and calcium entry is suppressed by lectins but not by removal of sialic acids. (a) Migration of MDA-MB-231, MDA-MB-435s and MCF7 induced by LL-37 (10 $\mu \mathrm{g} / \mathrm{mL})$ with or without lectins ( $5 \mu \mathrm{g} / \mathrm{mL}$ ), MAA I and MAA II (Maackia amurensis I and II), SNA (Sambucus nigra Agglutinin) and PNA (Peanut Agglutinin) ( $\mathrm{N}=8,6$ or 3). (b) Calcium entry in MDA-MB-231 and MDA-MB-435s $(\mathrm{N}=4)$ at conditions as in (a). To the right, a display of the time course of fura-2 fluorescence ratio detected at $510 \mathrm{~nm}$ with both excitations at 340 and $380 \mathrm{~nm}$ is shown. The graph to the right shows representative curves for the time course of the fura- 2 fluorescence ratio at $510 \mathrm{~nm}$ with excitations at 340 and $380 \mathrm{~nm}$. (c) Migration of MDA-MB-231 and MDA-MB-435s induced by LL-37 $(10 \mu \mathrm{g} / \mathrm{mL})$ after treatment with sialidases of Arthrobacter ureafaciens or Vibrio cholerae (treatment at $0.1 \mathrm{UI} / \mathrm{mL}$ for $1 \mathrm{~h}$ ) that preferentially digested $\alpha 2-6$ and $\alpha 2-3$ sialic acids, respectively $(\mathrm{N}=4)$. Data (migration and calcium entry) were normalized to the effect of LL-37. Statistics are relative to control without LL-37, with ${ }^{* * *} p<0.001,{ }^{* *} p<0.01,{ }^{*} p<0.05$, and relative to the effect by LL-37.

\subsection{Membrane Chondroitin Sulfate and/or Heparin Are Involved in Membrane Binding of LL-37 and Are Needed for Its Activities}

Since some previous studies have demonstrated an interaction between sulfated oligosaccharides of mammalian cells and LL-37 [21,31], the first experiments were performed using different free sulfated glycoaminoglycans such as chondroitin and heparin. In the three cell lines, both chondroitins and heparin totally abrogated LL-37 effects on migration (Figure 2a) or calcium influx (Figure 2b), except for heparin on MDA-MB-435s migration. Control migration experiments with 5\% FCS, as chemoattractant revealed that this inhibitions was not due to decrease of migratory capacities of the cells (Supplementary Figure S1b). Moreover, the inhibition was linked to a reduced binding of LL-37 to the cell surface as shown an immunofluorescence analysis performed on nonpermeabilized MDA-MB-231 cells (Figure 2c). As previously reported, LL-37 attached to the cells in a heterogenous manner, reflecting its accumulation 
at specific sites of the cell surface [8]. As shown in Figure 2c, membrane fixation of LL-37 was strongly reduced by chondroitins and heparin (Figure 2c).

a

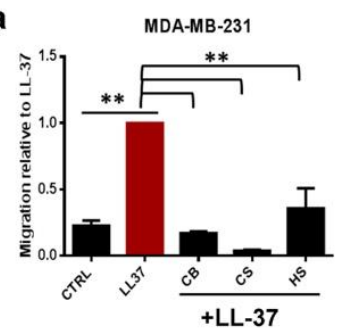

b

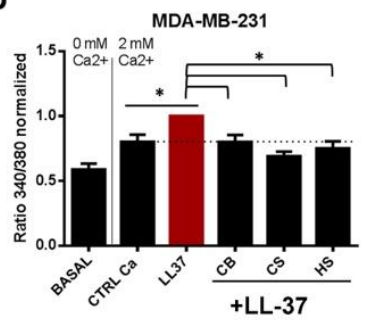

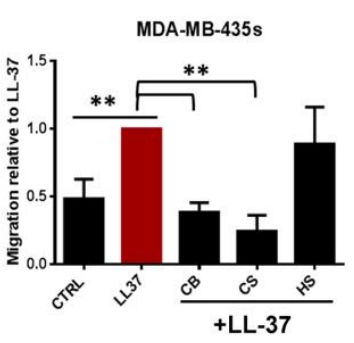

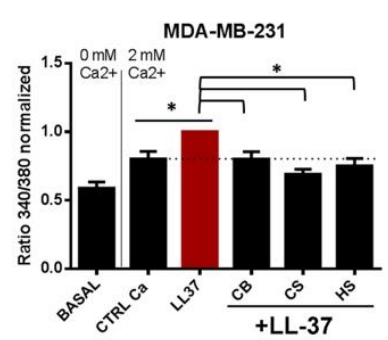

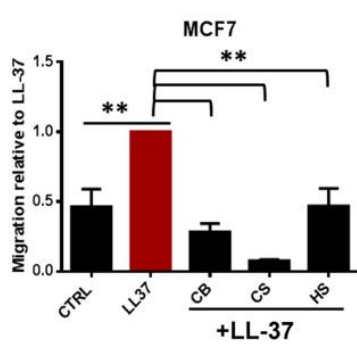

C
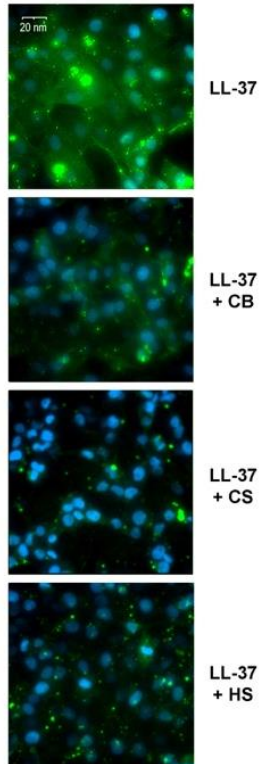

Figure 2. Glycoaminoglycans (chondroitin sulfate and heparin) inhibit LL-37 induced-calcium entry and migration and reduce its attachment to the cell surface. (a). Migration of MDA-MB-231, MDA-MB-435s and MCF7 cell lines induced by LL-37 and incubated or not with different glycoaminoglycans (CB — chondroitin sulfate B at $0.5 \mathrm{mg} / \mathrm{mL}, \mathrm{CS}$ — chondroitin sulfate from shark cartilage at $0.5 \mathrm{mg} / \mathrm{mL}$, HS-heparin at $50 \mathrm{UI} / \mathrm{mL}(\mathrm{N}=4)$ ). (b) Calcium entry in MDA-MB-231 and MDA-MB-435s induced by LL-37 $(10 \mu \mathrm{g} / \mathrm{mL})$ with or without glycoaminoglycans with concentrations as used for migration $(\mathrm{N}=3)$. (c) Immunofluorescence labeling with anti-LL-37 [22] plus secondary antibody (Alexa488-green) on MDA-MB-231, incubated with or without different glycoaminoglycans with same concentrations as used for migration. Nuclei were labeled by DAPI (in blue). Magnification $400 \times$. Data (migration and calcium entry) are normalized to LL-37. Statistics: ${ }^{* *} p<0.01,{ }^{*} p<0.05$, relative to LL-37 and relative to control without LL-37.

To ascertain that glycoaminoglycans did not act only as competitors but were biological actors in LL-37 activities, several strategies were elaborated to reduce or modify glycoaminoglycans on the cell membranes. The first one involved enzymatic digestion of chondroitins by chondroitinase ABC and heparin or heparan by heparinase I/III. Whereas chondroitinases ABC inhibited LL-37-induced migration by $65 \%$ and 53\% in MDA-MB-231 and MDA-MB-435s, respectively, no effect of this enzyme was observed in MCF7 cells (Figure 3a). Inversely, heparinases presented no inhibitory effect in LL-37-induced migration on MDA-MB-231 and MDA-MB-435s but abrogated 80\% of LL-37-induced migration in MCF7 (Figure 3a). The migration inhibition was specific on LL-37 since in corresponding experiments, using FCS as attractant, no inhibition or even a slight increase was observed (Supplementary Figure S1b). In correspondence, fluorescence microscopy revealed that on MDA-MB-231 only chondroitinases were able to suppress its binding to the cell membrane, while heparinase showed no effect (Figure 3b). 
a
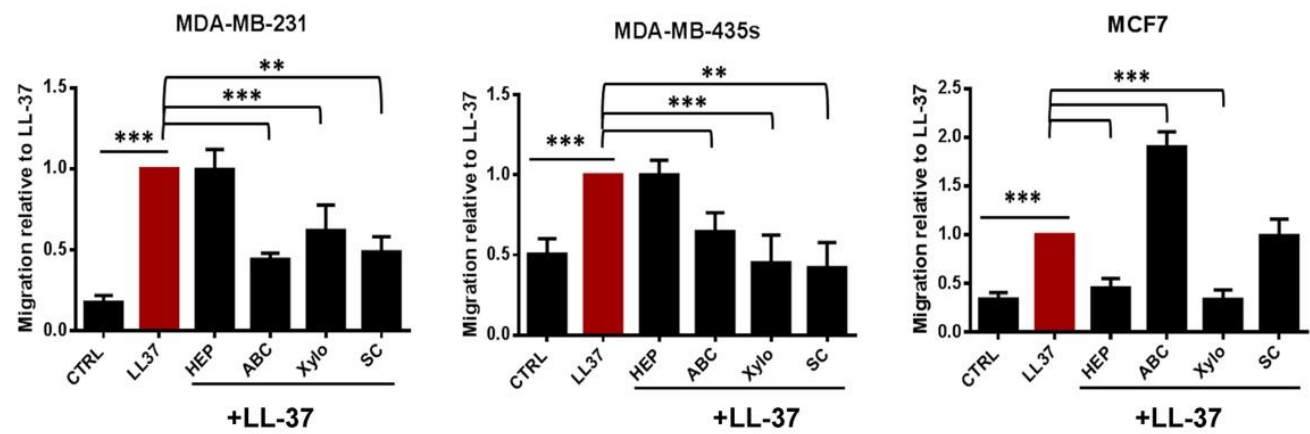

b

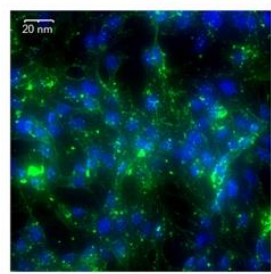

LL-37

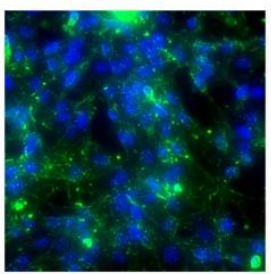

LL-37 + HEP

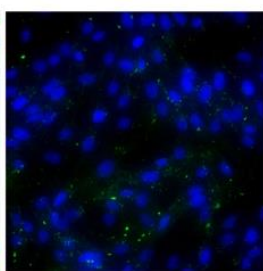

$\mathrm{LL}-37+\mathrm{ABC}$

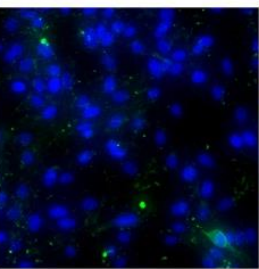

LL-37 + Xylo

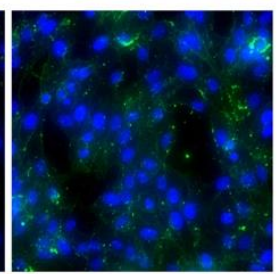

LL-37 + SC

Figure 3. Digestion of membrane chondroitin sulfate and heparin and inhibition of glycoaminoglycan synthesis decrease membrane fixation of LL-37 and cell migration. (a) Migration of MDA-MB-231, MDA-MB-435s and MCF7 cell lines induced by LL-37. Cells were previously incubated or not with different enzymes digesting glycoaminoglycans (Hep: heparinases I/III, treatment $5 \mathrm{mUI} / \mathrm{mL} 1 \mathrm{~h}, \mathrm{ABC}$ : chondroitinase $\mathrm{ABC}$, treatment $1 \mathrm{UI} / \mathrm{mL} 1 \mathrm{~h}$, Xylo: 4-Methylumbelliferyl- $\beta$-D-xyloside $0.5 \mathrm{mM}$ ) or with an inhibitor of sulfatation (SC—sodium chlorate $30 \mathrm{mM})(\mathrm{N}=4)$. (b) Immunofluorescence labeling with anti-LL-37 on MDA-MB-231 cells previously treated or not as in (a). Magnification $\times 400$. Data are normalized to LL-37. Statistics: ${ }^{* * *} p<0.001,{ }^{* *} p<0.01,{ }^{*} p<0.05$, relative to LL-37 and relative to control without LL-37, respectively.

The second strategy was to block glycosylation synthesis of proteoglycans using a modified xylose (4-Methylumbelliferyl- $\beta$-D-xyloside) as xylose is the first and necessary glycan to connect glycoaminoglycans on proteoglycans [32]. In the three cell lines, xyloside strongly reduced LL-37-induced migration by $45 \%, 82 \%$ and $100 \%$ in MDA-MB-231, MDA-MB- 435 s and MCF7, respectively (Figure 3a). Regarding LL-37-induced calcium influx, xyloside inhibited by $30 \%$ and $50 \%$ calcium influx in MDA-MB-231 and MDA-MB-435s.

Finally, the last strategy was to suppress the sulfatation of glycoaminoglycans using sodium chlorate [33]. Except for MCF7, in which sodium chlorate did not affect LL-37-induced migration, pretreatment with $\mathrm{NaClO}_{3}$ led to a decrease by $60 \%$ and $86 \%$ of migration of MDA-MB-231 and MDA-MB-435s (Figure 3a). Concordantly, calcium influx was decreased by $80 \%$ and $50 \%$ in these cell lines (Supplementary Figure S3).

Taken together, these results suggested that LL-37 needed membrane glycoaminoglycans to exercise its activities. Their nature, however, appears to differ among the cell lines, as chondroitins seemed to be more implicated for MDA-MB-231 and MDA-MB-435s cells and heparin/heparan for MCF7. The effects were specific to LL-37 since none of these treatments (glycoaminoglycans digestion, synthesis blockage or sulfatation inhibition) interfered with cell migration capabilities when $5 \%$ FCS was used as chemoattractant (Supplementary Figure S1b).

\subsection{Identification of Syndecan-4 as Proteoglycan Implicated in Membrane Fixation and LL-37-Induced Activities}

Growing evidence has shown that proteoglycans (PGs) and glycoaminoglycans (GAGs) are essential partners during tumor progression [34]. Among PGs, syndecan-1 and -4 are associated with 
breast cancer $[35,36]$ and cell adhesion and mobility [37,38] and were, therefore, selected as candidates for the activities of LL-37. RNA interference against syndecan-4 (the efficacy of RNAi for both genes presented in Supplementary Figure S4) reduced LL-37-induced migration by 40-50\% in the three cell lines. No reduced migration was observed when targeting syndecan-1 (Figure 4a) in MCF7 and MDA-MB-231, and a non-significant tendency to reduction in MDA-MB-435s. Control experiments with FCS as chemoattractant confirmed that the reduced migration was specific for treatment with LL-37 (Supplementary Figure S1c).

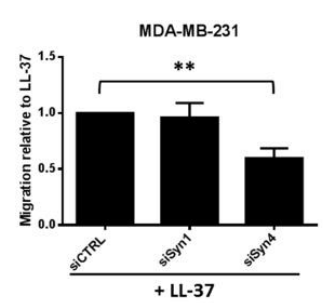

b

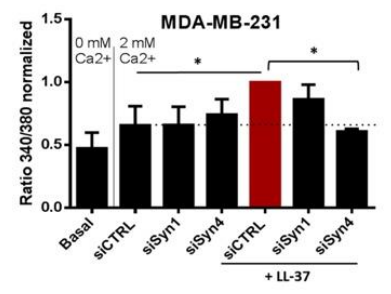

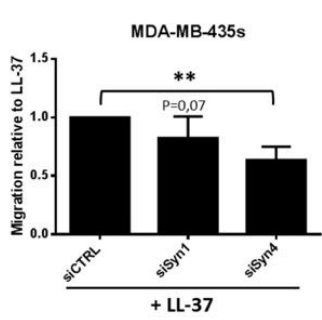
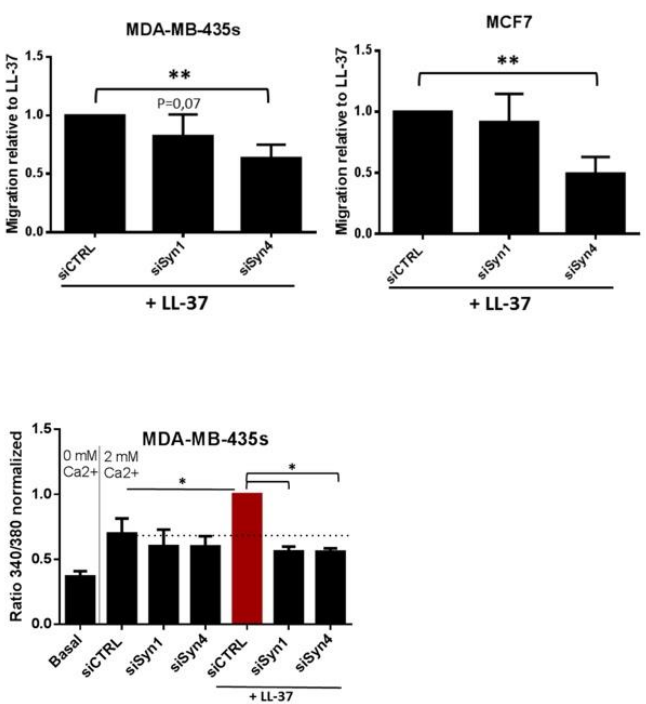
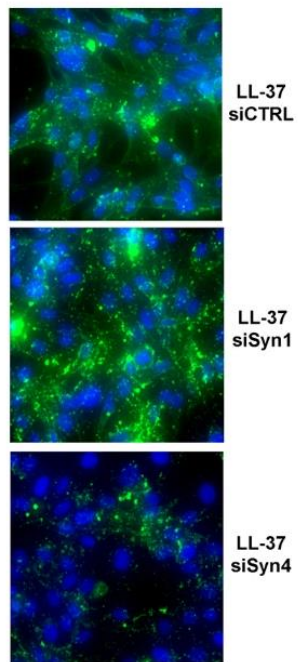

Figure 4. Syndecan-4 is implicated in LL-37 induced-calcium entry and cell migration. Effects of RNA interference against syndecan- 1 and 4 on (a) LL-37-induced migration of MDA-MB-231, MDA-MB-435s and MCF7 $(\mathrm{N}=5)$. (b) Calcium entry in MDA-MB-231, MDA-MB-435s cell lines induced by LL-37 $(\mathrm{N}=3)$. (c) Immunofluorescence labeling with anti-LL-37 (Alexa488-green) on MDA-MB-231, treated with siRNA against syndecans-1 and 4. Nuclei labeled by DAPI (in blue). Magnification 400x. Data are normalized to the effects of LL-37. Statistics: ${ }^{* *} p<0.01,{ }^{*} p<0.05$.

LL-37-induced calcium influx was entirely abolished in MDA-MB-435s when targeting syndecan-1 or syndecan-4. In MDA-MB-231, suppression of syndecan-1 resulted in less decrease of calcium influx than suppression of syndecan-4 (Figure $4 \mathrm{~b}$ ). The immunofluorescence analysis revealed that binding LL-37 to the surface of MDA-MB-231 was strongly reduced after RNA interference against syndecan-4. In contrast suppression of syndecan-1 rather appeared to increase LL-37 binding. (Figure 4c). We conclude that the attachment of LL-37 to syndecan-4 is a common denominator for mediating its activities in all experiments performed.

In addition, the impact of syndecan- 4 on cell migration was assayed on MDA-MB-435s using the D-enantiomer of LL-37. RNA interference against syndecan-4 (completed with the use of a second siRNA) identically suppressed the promigratory activities of both enantiomers in an identical manner (Supplementary Figure S5).

\section{Discussion}

Our investigation has revealed that surface glycans are required for the promigratory activities of LL-37. The concentration of LL-37, as used in this and our previous studies, is well within the physiological concentrations observed in vivo [39,40], being highly elevated in breast cancer [41]. Stimulatory effects at this concentration have been published on growth and/or migration of primary epithelial cells and cell lines [8,41,42], while cytotoxic effects were observed at concentrations higher than used in this study [39], (GW, data not shown). It thus appears reasonable to assume that the data presented here are in agreement with physiological conditions. 
The electrostatic interaction between sialic acids and cationic antimicrobial peptides has been demonstrated before [43]. In fact, the removal of both sialic acids and sulfated glycans decreased the binding of LL-37 to the cell surface, which may reflect these unselective electrostatic interactions. However, only sulfated structures contribute to the activities of LL-37 we assayed. Among these, O-sulfatation appears involved since the inhibition by sodium chlorate selectively affects O-sulfotransferases [33]. In conclusion, the activities of LL-37 require its binding to rather specific glycan structures.

In a candidate approach, we have identified syndecan- 4 as a proteoglycan that critically mediates the activities of LL-37. Its localization, binding properties and activities may help to explain a number of previous findings of the behavior of LL-37. Similar to LL-37, syndecan-4 induces cell migration [44] and is known to cluster at lipid rafts prior to its endocytosis [45], which agrees with our localization studies for LL-37 [8]. Moreover, syndecan-4 can activate various signaling pathways, both by binding various growth factors [46] and by directly interacting with tyrosine kinase receptors as a co-receptor $[47,48]$. The fact that the D- and L- enantiomer of LL-37 shows identical activities has been attributed to its interaction with the lipid bilayer of the cellular membrane [6-8]. In our present study, however, both enantiomers lost their activity after suppression of syndecan-4, suggesting that both bind equally to the glycan structures of syndecan-4. Such behavior has previously been reported for both enantiomers of a small cell-penetrating peptide, the cellular uptake of which require binding to the heparan sulfate structures of syndecan-4 [49].

In the light of these findings, we hypothesize that syndecan-4, via its GAGs moieties, serves as a primary target for mediating the activities of LL-37. This does certainly not contradict previous findings of its attachment to the cellular membrane-glycans may actually serve as a "guide" for LL-37 to support its attachment to lipid rafts that otherwise would have been avoided by the peptide, as suggested by the experiments on artificial membranes [14].

MAA I and MAA II lectins, which inhibited the activities of LL-37, are best characterized as binding to terminal $\alpha 2-3$ sialic acid linked to galactose. Binding of MAA II has been also reported to sulfated galactose $[29,50]$, but, to our knowledge, not to chondroitin sulfate or heparan sulfate. These lectins thus do not appear to directly compete with LL-37 on its binding site, and therefore, the implication of sialylated structures for LL-37 activities requires deeper investigations in our models.

The responsible glycan structures involved in the activities of LL-37 appear to vary, since heparinase abolished LL-37-induced migration in MCF7, whereas chondroitinases and sodium chlorate were more efficient on MDA-MB-231 and MD1-MB-435s. Chondroitin sulfates have been reported as more abundant and more expressed in MDA-MB-231 as compared to MCF7 [51]. For breast cancer in general, alterations in the expression of glycan modifiers and sulfatation patterns has been correlated to the metastatic potential of the tumor [52], thus, our findings might reflect these differences.

Heparan Sulfate Proteoglycans have been suggested as mediating the immunomodulatory effects of LL-37 [53] although their nature remained unknown. Our discovery of syndecan-4 as a major player for LL-37 does not exclude that other proteoglycans are involved as well. This notion is supported for example on MCF7 cells where heparinase and xyloside inhibited its activities more effectively than RNA interference against syndecan- 4 . We also noted that the suppression of syndecan- 1 appeared to modify - rather increase - binding of LL-37 to the cell surface of MDA-MB-231—certainly without increasing the activities of LL-37. In absence of evidence, it might be hypothesized that syndecan-1 modifies the access of the peptide to the cell surface, but without involving the locations where the peptide induces cell migration and calcium influx (i.e., caveolae and pseudopodia [8]). Irrespective of some differences in response of the cell lines to inhibitors of cell surface glycan structures, syndecan- 4 appears to be a common denominator for the activities of LL-37 we have assayed thus far.

LL-37 is rapidly internalized [8], an aspect it shares with small cell penetrating peptides. Although these peptides are structurally unrelated to LL-37, their positive charge could be seen as a denominator in common. Their internalization has been shown to depend on their association with 
glucosaminoglycans $[54,55]$, or more specifically with syndecans [56]. These findings may provide some insight to the affinities of LL-37.

\section{Conclusions}

Changes in glycosylation and the remodeling of glycans are part of cancer development [57], and the expression of some of these antigens and their modifying enzymes has been associated with the metastatic nature of the tumor [52] and poor prognosis [58]. Proteoglycans in particular and signaling pathways emerging from them contribute to the motility of breast cancer cells and thus their metastatic potential [34]. Our results indicate that LL-37 could be an integral part of their activities.

Supplementary Materials: The following are available online at http://www.mdpi.com/2218-273X/9/9/481/s1.

Author Contributions: Conceptualization, C.G. and G.W.; methodology, all; validation, all, formal analysis, all; investigation, C.H. and G.W.; data curation, all; writing-original draft preparation G.W.; writing-review and editing, all; visualization, C.H. and G.W.; supervision, C.G. and G.W.; funding acquisition, G.W.

Funding: This work was funded by the University of Tours, INSERM, and the "Ligue contre le Cancer", departments 16, 53, 56 and 85. Chahrazed Habes holds a fellowship from the Région Centre-Val de Loire. Caroline Goupille was supported by the University Hospital "CHRU de Tours - Hôpital Bretonneau".

Acknowledgments: The monoclonal antibody anti-LL37 was a generous gift from Birgitta Agerberth, Karolinska Institutet. We express our gratitude to Isabelle Domingo for her technical assistance in cell culture and migration, Laurie Lajoie for her support in FACS analysis, Marie Potier-Cartereau for her advice in calcium signaling and Catherine Leroy for secretarial support. We also thank our students Dominique Bomia, Victor Tiroille, Philippa Schnelle, Marion Lambault, Marine Jakubec and Odin Preux for their experimental contributions during their internships.

Conflicts of Interest: The authors declare no conflict of interest.

\section{References}

1. Xhindoli, D.; Pacor, S.; Benincasa, M.; Scocchi, M.; Gennaro, R.; Tossi, A. The human cathelicidin LL-37-A pore-forming antibacterial peptide and host-cell modulator. Biochim. Biophys. Acta (BBA)-Biomembr. 2016, 1858, 546-566. [CrossRef] [PubMed]

2. Fabisiak, A.; Murawska, N.; Fichna, J. LL-37: Cathelicidin-related antimicrobial peptide with pleiotropic activity. Pharmacol. Rep. 2016, 68, 802-808. [CrossRef] [PubMed]

3. Piktel, E.; Niemirowicz, K.; Wnorowska, U.; Watek, M.; Wollny, T.; Gluszek, K.; Gozdz, S.; Levental, I.; Bucki, R. The Role of Cathelicidin LL-37 in Cancer Development. Arch. Immunol. Ther. Exp. 2016, 64, $33-46$. [CrossRef]

4. Chen, X.; Zou, X.; Qi, G.; Tang, Y.; Guo, Y.; Si, J.; Liang, L. Roles and Mechanisms of Human Cathelicidin LL-37 in Cancer. Cell. Physiol. Biochem. 2018, 47, 1060-1073. [CrossRef] [PubMed]

5. Verjans, E.-T.; Zels, S.; Luyten, W.; Landuyt, B.; Schoofs, L. Molecular mechanisms of LL-37-induced receptor activation: An overview. Peptides 2016, 85, 16-26. [CrossRef] [PubMed]

6. Von Haussen, J.; Koczulla, R.; Shaykhiev, R.; Herr, C.; Pinkenburg, O.; Reimer, D.; Wiewrodt, R.; Biesterfeld, S.; Aigner, A.; Czubayko, F.; et al. The host defence peptide LL-37/hCAP-18 is a growth factor for lung cancer cells. Lung Cancer 2008, 59, 12-23. [CrossRef] [PubMed]

7. Tomasinsig, L.; Pizzirani, C.; Skerlavaj, B.; Pellegatti, P.; Gulinelli, S.; Tossi, A.; Di Virgilio, F.; Zanetti, M. The Human Cathelicidin LL-37 Modulates the Activities of the P2 $\times 7$ Receptor in a Structure-dependent Manner. J. Boil. Chem. 2008, 283, 30471-30481. [CrossRef] [PubMed]

8. Gambade, A.; Zreika, S.; Gueguinou, M.; Chourpa, I.; Fromont, G.; Bouchet, A.M.; Burlaud-Gaillard, J.; Potier-Cartereau, M.; Roger, S.; Aucagne, V.; et al. Activation of TRPV2 and BKCa channels by the LL-37 enantiomers stimulates calcium entry and migration of cancer cells. Oncotarget 2016, 7, 23785-23800. [CrossRef]

9. Di Nardo, A.; Braff, M.H.; Taylor, K.R.; Na, C.; Granstein, R.D.; McInturff, J.E.; Krutzik, S.; Modlin, R.L.; Gallo, R.L. Cathelicidin antimicrobial peptides block dendritic cell TLR4 activation and allergic contact sensitization. J. Immunol. 2007, 178, 1829-1834. [CrossRef] 
10. Sancho-Vaello, E.; François, P.; Bonetti, E.-J.; Lilie, H.; Finger, S.; Gil-Ortiz, F.; Gil-Carton, D.; Zeth, K. Structural remodeling and oligomerization of human cathelicidin on membranes suggest fibril-like structures as active species. Sci. Rep. 2017, 7, 15371. [CrossRef]

11. Wildman, K.A.H.; Lee, D.-K.; Ramamoorthy, A. Mechanism of Lipid Bilayer Disruption by the Human Antimicrobial Peptide, LL-37. Biochemistry 2003, 42, 6545-6558. [CrossRef]

12. Henzler-Wildman, K.A.; Martinez, G.V.; Brown, M.F.; Ramamoorthy, A. Perturbation of the Hydrophobic Core of Lipid Bilayers by the Human Antimicrobial Peptide LL-37. Biochemistry 2004, 43, 8459-8469. [CrossRef]

13. Sood, R.; Domanov, Y.; Pietiäinen, M.; Kontinen, V.P.; Kinnunen, P.K. Binding of LL-37 to model biomembranes: Insight into target vs. host cell recognition. Biochim. Biophys. Acta (BBA)-Biomembr. 2008, 1778, 983-996. [CrossRef]

14. Sood, R.; Kinnunen, P.K. Cholesterol, lanosterol, and ergosterol attenuate the membrane association of LL-37(W27F) and temporin L. Biochim. Biophys. Acta 2008, 1778, 1460-1466. [CrossRef]

15. Simons, K.; Toomre, D. Lipid rafts and signal transduction. Nat. Rev. Mol. Cell Boil. 2000, 1, 31-39. [CrossRef]

16. Pike, L.J. The challenge of lipid rafts. J. Lipid Res. 2009, 50, S323-S328. [CrossRef]

17. Gueguinou, M.; Gambade, A.; Felix, R.; Chantome, A.; Fourbon, Y.; Bougnoux, P.; Weber, G.; Potier-Cartereau, M.; Vandier, C. Lipid rafts, $\mathrm{KCa} / \mathrm{ClCa} / \mathrm{Ca}^{2+}$ channel complexes and EGFR signaling: Novel targets to reduce tumor development by lipids? Biochim. Biophys. Acta 2015, 1848, 2603-2620. [CrossRef]

18. Felgentreff, K.; Beisswenger, C.; Griese, M.; Gulder, T.; Bringmann, G.; Bals, R. The antimicrobial peptide cathelicidin interacts with airway mucus. Peptides 2006, 27, 3100-3106. [CrossRef]

19. Thomas, A.J.; Pulsipher, A.; Davis, B.M.; Alt, J.A. LL-37 causes cell death of human nasal epithelial cells, which is inhibited with a synthetic glycosaminoglycan. PLoS ONE 2017, 12, e0183542. [CrossRef]

20. Sandgren, S.; Wittrup, A.; Cheng, F.; Jönsson, M.; Eklund, E.; Busch, S.; Belting, M. The Human Antimicrobial Peptide LL-37 Transfers Extracellular DNA Plasmid to the Nuclear Compartment of Mammalian Cells via Lipid Rafts and Proteoglycan-dependent Endocytosis. J. Boil. Chem. 2004, 279, 17951-17956. [CrossRef]

21. Suzuki, K.; Murakami, T.; Hu, Z.; Tamura, H.; Kuwahara-Arai, K.; Iba, T.; Nagaoka, I. Human Host Defense Cathelicidin Peptide LL-37 Enhances the Lipopolysaccharide Uptake by Liver Sinusoidal Endothelial Cells without Cell Activation. J. Immunol. 2016, 196, 1338-1347. [CrossRef]

22. Yoshio, H.; Tollin, M.; Gudmundsson, G.H.; Lagercrantz, H.; Jörnvall, H.; Marchini, A.G.; Agerberth, B. Antimicrobial Polypeptides of Human Vernix Caseosa and Amniotic Fluid: Implications for Newborn Innate Defense. Pediatr. Res. 2003, 53, 211-216. [CrossRef]

23. Beauvais, D.M.; Burbach, B.J.; Rapraeger, A.C. The syndecan-1 ectodomain regulates alpha beta $_{3}$ integrin $_{\text {in }}$ activity in human mammary carcinoma cells. J. Cell Biol. 2004, 167, 171-181. [CrossRef]

24. Rauch, B.H.; Millette, E.; Kenagy, R.D.; Daum, G.; Fischer, J.W.; Clowes, A.W. Syndecan-4 Is Required for Thrombin-induced Migration and Proliferation in Human Vascular Smooth Muscle Cells. J. Boil. Chem. 2005, 280, 17507-17511. [CrossRef]

25. Livak, K.J.; Schmittgen, T.D. Analysis of relative gene expression data using real-time quantitative PCR and the 2(-Delta Delta C(T)) Method. Methods 2001, 25, 402-408. [CrossRef]

26. Christiansen, M.N.; Chik, J.; Lee, L.Y.; Anugraham, M.; Abrahams, J.L.; Packer, N.H. Cell surface protein glycosylation in cancer. Proteomics 2014, 14, 525-546. [CrossRef]

27. Guo, H.; Abbott, K.L. Functional Impact of Tumor-Specific N-Linked Glycan Changes in Breast and Ovarian Cancers. Adv. Cancer Res. 2015, 126, 281-303.

28. Okolicsanyi, R.K.; Van Wijnen, A.J.; Cool, S.M.; Stein, G.S.; Griffiths, L.R.; Haupt, L.M. Heparan Sulfate Proteoglycans and Human Breast Cancer Epithelial Cell Tumorigenicity. J. Cell. Biochem. 2014, 115, 967-976. [CrossRef]

29. Geisler, C.; Jarvis, D.L. Effective glycoanalysis with Maackia amurensis lectins requires a clear understanding of their binding specificities. Glycobiology 2011, 21, 988-993. [CrossRef]

30. Kim, S.; Oh, D.-B.; Kang, H.A.; Kwon, O. Features and applications of bacterial sialidases. Appl. Microbiol. Biotechnol. 2011, 91, 1-15. [CrossRef]

31. Lishko, V.K.; Moreno, B.; Podolnikova, N.P.; Ugarova, T.P. Identification of Human Cathelicidin Peptide LL-37 as a Ligand for Macrophage Integrin $\alpha \mathrm{M} \beta 2$ (Mac-1, CD11b/CD18) that Promotes Phagocytosis by Opsonizing Bacteria. Res. Rep. Biochem. 2016, 2016, 39-55. 
32. Lohmander, L.S.; Hascall, V.C.; Caplan, A.I. Effects of 4-methylumbelliferyl-beta-D-xylopyranoside on chondrogenesis and proteoglycan synthesis in chick limb bud mesenchymal cell cultures. J. Boil. Chem. 1979, 254, 10551-10561.

33. Safaiyan, F.; Kolset, S.O.; Prydz, K.; Gottfridsson, E.; Lindahl, U.; Salmivirta, M. Selective Effects of Sodium Chlorate Treatment on the Sulfation of Heparan Sulfate. J. Boil. Chem. 1999, 274, 36267-36273. [CrossRef]

34. Nikitovic, D.; Kouvidi, K.; Voudouri, K.; Berdiaki, A.; Karousou, E.; Passi, A.; Tzanakakis, G.N. The Motile Breast Cancer Phenotype Roles of Proteoglycans/Glycosaminoglycans. BioMed Res. Int. 2014, 2014, 1-13. [CrossRef]

35. Lendorf, M.E.; Manon-Jensen, T.; Kronqvist, P.; Multhaupt, H.A.B.; Couchman, J.R. Syndecan-1 and Syndecan-4 Are Independent Indicators in Breast Carcinoma. J. Histochem. Cytochem. 2011, 59, 615-629. [CrossRef]

36. Okolicsanyi, R.K.; Buffiere, A.; Jacinto, J.M.; Chacon-Cortes, D.; Chambers, S.K.; Youl, P.H.; Haupt, L.M.; Griffiths, L.R. Association of heparan sulfate proteoglycans SDC1 and SDC4 polymorphisms with breast cancer in an Australian Caucasian population. Tumor Biol. 2015, 36, 1731-1738. [CrossRef]

37. Vuoriluoto, K.; Högnäs, G.; Meller, P.; Lehti, K.; Ivaska, J. Syndecan-1 and -4 differentially regulate oncogenic K-ras dependent cell invasion into collagen through $\alpha 2 \beta 1$ integrin and MT1-MMP. Matrix Boil. 2011, 30, 207-217. [CrossRef]

38. Hassan, H.; Greve, B.; Pavão, M.S.G.; Kiesel, L.; Ibrahim, S.A.; Götte, M. Syndecan-1 modulates $\beta$-integrin-dependent and interleukin-6-dependent functions in breast cancer cell adhesion, migration, and resistance to irradiation. FEBS J. 2013, 280, 2216-2227. [CrossRef]

39. Barlow, P.G.; Beaumont, P.E.; Cosseau, C.; Mackellar, A.; Wilkinson, T.S.; Hancock, R.E.W.; Haslett, C.; Govan, J.R.W.; Simpson, A.J.; Davidson, D.J. The Human Cathelicidin LL-37 Preferentially Promotes Apoptosis of Infected Airway Epithelium. Am. J. Respir. Cell Mol. Boil. 2010, 43, 692-702. [CrossRef]

40. Malm, J.; Sorensen, O.E.; Persson, T.; Frohm-Nilsson, M.; Johansson, B.; Bjartell, A.; Lilja, H.; Ståhle-Bäckdahl, M.; Borregaard, N.; Egesten, A. The Human Cationic Antimicrobial Protein (hCAP-18) Is Expressed in the Epithelium of Human Epididymis, Is Present in Seminal Plasma at High Concentrations, and Is Attached to Spermatozoa. Infect. Immun. 2000, 68, 4297-4302. [CrossRef]

41. Heilborn, J.D.; Nilsson, M.F.; Jimenez, C.I.; Sandstedt, B.; Borregaard, N.; Tham, E.; Sorensen, O.E.; Weber, G.; Stahle, M. Antimicrobial protein hCAP18/LL-37 is highly expressed in breast cancer and is a putative growth factor for epithelial cells. Int. J. Cancer 2005, 114, 713-719. [CrossRef]

42. Coffelt, S.B.; Tomchuck, S.L.; Zwezdaryk, K.J.; Danka, E.S.; Scandurro, A.B. Leucine Leucine-37 Uses Formyl Peptide Receptor-Like 1 to Activate Signal Transduction Pathways, Stimulate Oncogenic Gene Expression, and Enhance the Invasiveness of Ovarian Cancer Cells. Mol. Cancer Res. 2009, 7, 907-915. [CrossRef]

43. Weghuber, J.; Aichinger, M.C.; Brameshuber, M.; Wieser, S.; Ruprecht, V.; Plochberger, B.; Madl, J.; Horner, A.; Reipert, S.; Lohner, K.; et al. Cationic amphipathic peptides accumulate sialylated proteins and lipids in the plasma membrane of eukaryotic host cells. Biochim. Biophys. Acta (BBA)-Biomembr. 2011, 1808, 2581-2590. [CrossRef]

44. Tkachenko, E.; Elfenbein, A.; Tirziu, D.; Simons, M. Syndecan-4 Clustering Induces Cell Migration in a PDZ-Dependent Manner. Circ. Res. 2006, 98, 1398-1404. [CrossRef]

45. Tkachenko, E. Fibroblast growth factor 2 endocytosis in endothelial cells proceed via syndecan-4-dependent activation of Rac1 and a Cdc42-dependent macropinocytic pathway. J. Cell Sci. 2004, 117, 3189-3199. [CrossRef]

46. Elfenbein, A.; Simons, M. Syndecan-4 signaling at a glance. J. Cell Sci. 2013, 126, 3799-3804. [CrossRef]

47. Wang, H.; Jin, H.; Rapraeger, A.C. Syndecan-1 and Syndecan-4 Capture Epidermal Growth Factor Receptor Family Members and the $\alpha 3 \beta 1$ Integrin via Binding Sites in Their Ectodomains. J. Boil. Chem. 2015, 290, 26103-26113. [CrossRef]

48. Tsonis, A.I.; Afratis, N.; Gialeli, C.; Piperigkou, Z.; Skandalis, S.S.; Theocharis, A.D.; Tzanakakis, G.N.; Karamanos, N.K.; Ellina, M.-I.; Ellina, M. Evaluation of the coordinated actions of estrogen receptors with epidermal growth factor receptor and insulin-like growth factor receptor in the expression of cell surface heparan sulfate proteoglycans and cell motility in breast cancer cells. FEBS J. 2013, 280, 2248-2259. [CrossRef]

49. Montrose, K.; Yang, Y.; Sun, X.; Wiles, S.; Krissansen, G.W. Xentry, a new class of cell-penetrating peptide uniquely equipped for delivery of drugs. Sci. Rep. 2013, 3, 3. [CrossRef] 
50. Maenuma, K.; Yim, M.; Komatsu, K.; Hoshino, M.; Takahashi, Y.; Bovin, N.; Irimura, T. Use of a library of mutated Maackia amurensis hemagglutinin for profiling the cell lineage and differentiation. Proteomics 2008, 8, 3274-3283. [CrossRef]

51. Cooney, C.A.; Jousheghany, F.; Yao-Borengasser, A.; Phanavanh, B.; Gomes, T.; Kieber-Emmons, A.M.; Siegel, E.R.; Suva, L.J.; Ferrone, S.; Kieber-Emmons, T.; et al. Chondroitin sulfates play a major role in breast cancer metastasis: A role for CSPG4 and CHST11 gene expression in forming surface P-selectin ligands in aggressive breast cancer cells. Breast Cancer Res. 2011, 13, R58. [CrossRef]

52. Fernandez-Vega, I.; García, O.; Crespo, A.; Castañón, S.; Menéndez, P.; Astudillo, A.; Quirós, L.M. Specific genes involved in synthesis and editing of heparan sulfate proteoglycans show altered expression patterns in breast cancer. BMC Cancer 2013, 13, 24. [CrossRef]

53. Kaneider, N.C.; Djanani, A.; Wiedermann, C.J. Heparan Sulfate Proteoglycan-Involving Immunomodulation by Cathelicidin Antimicrobial Peptides LL-37 and PR-39. Sci. World J. 2007, 7, 1832-1838. [CrossRef]

54. Nakase, I.; Tadokoro, A.; Kawabata, N.; Takeuchi, T.; Katoh, H.; Hiramoto, K.; Negishi, M.; Nomizu, M.; Sugiura, Y.; Futaki, S. Interaction of Arginine-Rich Peptides with Membrane-Associated Proteoglycans Is Crucial for Induction of Actin Organization and Macropinocytosis. Biochemistry 2007, 46, 492-501. [CrossRef]

55. Amoura, M.; Illien, F.; Joliot, A.; Guitot, K.; Offer, J.; Sagan, S.; Burlina, F. Head to tail cyclisation of cell-penetrating peptides: Impact on GAG-dependent internalisation and direct translocation. Chem. Commun. 2019, 55, 4566-4569. [CrossRef]

56. Letoha, T.; Keller-Pintér, A.; Kúsz, E.; Kolozsi, C.; Bozsó, Z.; Toth, G.; Vizler, C.; Oláh, Z.; Szilák, L. Cell-penetrating peptide exploited syndecans. Biochim. Biophys. Acta (BBA)-Biomembr. 2010, 1798, 2258-2265. [CrossRef]

57. Theocharis, A.D.; Karamanos, N.K. Proteoglycans remodeling in cancer: Underlying molecular mechanisms. Matrix Biol. 2019, 75-76, 220-259. [CrossRef]

58. Potapenko, I.O.; Lüders, T.; Russnes, H.G.; Helland, Å.; Sørlie, T.; Kristensen, V.N.; Nord, S.; Lingjærde, O.C.; Børresen-Dale, A.-L.; Haakensen, V.D. Glycan-related gene expression signatures in breast cancer subtypes; relation to survival. Mol. Oncol. 2015, 9, 861-876. [CrossRef] 